\title{
Smartphone Digital Image Colorimetry for the Determination of Aluminum in Antiperspirant Products
}

\author{
(iD Suad ABUGHRIN1,2, (D) Usama ALSHANA ${ }^{1,3 *}$, (D) Jude CALEB 1 \\ 1Near East University, Faculty of Pharmacy, Department of Analytical Chemistry, Nicosia, Cyprus \\ 2Center for Solar Energy Research and Studies, Libyan Authority for Scientific Research, Tripoli, Libya \\ 3 Sultan Qaboos University, College of Science, Department of Chemistry, Muscat, Oman
}

\begin{abstract}
Objectives: This study aims to present a method for the determination of the aluminum in antiperspirant products (APPs) by chelating it with quercetin before its detection by smartphone digital image colorimetry (SDIC).

Materials and Methods: Samples were prepared by closed-vessel acid digestion in PTFE cups. This was followed by complexation of aluminum in the sample solution using quercetin as a chelating agent. Sample solutions were transferred into a quartz ultraviolet/visible detection microcuvette for detection in a homemade colorimetric box designed for capturing images of the yellow complex with a smartphone camera. The pixel intensity of the images was converted to numbers for quantitation using ImageJ software for a personal computer. An independent study using highperformance liquid chromatography-diode-array detection was conducted to check the accuracy of the proposed method.

Results: Optimum SDIC conditions included a Samsung C9 smartphone as the detection camera, a cropped region of interest of 6400 px ${ }^{2}$, and the side position of the colorimetric box were selected for capturing the images of the sample solutions placed $10.0 \mathrm{~cm}$ from the detection camera, whereas optimum complexation conditions were found to be as sample $\mathrm{pH}$ of 5.5 , sample volume of $3.0 \mathrm{~mL}$, complexation time of $1.0 \mathrm{~min}$ and a ligand concentration of $0.28 \mathrm{mmol} \mathrm{L}^{-1}$. Analytical performance of the method included a limit of detection of $0.5 \mu \mathrm{mol} \mathrm{L}^{-1}$ and a coefficient of determination $\left(R^{2}\right)$ of the calibration graph of 0.9981 .

Conclusion: The proposed method was successfully applied for the determination of aluminum in APPs with percentage recoveries ranging from 80.0 to $109.6 \%$.
\end{abstract}

Key words: Aluminum, antiperspirant products, digital image colorimetry, quercetin, smartphone

\section{INTRODUCTION}

Aluminum and its compounds are widely used in various industries, including food, cosmetics, and pharmaceuticals.' Personal care products, such as deodorants and antiperspirant products (APPs), block the unpleasant body odor and reduce underarm sweat. They contain ingredients for pleasant odor, skin care, and beauty. ${ }^{2}$ The main active ingredients in APPs are aluminum and zirconium compounds. ${ }^{3}$ According to some studies, aluminum compounds can accumulate in the human body and are suspected of contributing to various pathological disorders including anemia, bone disease, breast cancer, encephalopathy, Alzheimer's, Parkinson's, and other neurological disorders. ${ }^{4,5}$ Despite the ongoing debate over the use of aluminum in APPs and the fact that the concentration of aluminum compounds in the final product is rarely reported, the number of analytical methods proposed for their determination in these samples remains very limited. Consequently, it is imperative to develop straightforward, rapid, and inexpensive analytical methods for this purpose to benefit consumers as well as governmental health agencies during the legislative process.

This work was partially presented at the $2^{\text {nd }}$ International Congress on Analytical and Bioanalytical Chemistry (2 ${ }^{\text {nd }}$ ICABC 11-14 March 2020) Antalya, Türkiye.

*Correspondence: u.alshana@squ.edu.om, Phone: +96824141511 (Ext. 2437),ORCID-ID: orcid.org/0000-0002-5633-2026

Received: 19.10.2021, Accepted: 12.11.2021

๑Turk J Pharm Sci, Published by Galenos Publishing House. 
Although flame-atomic absorption spectrometry (FAAS) is the most commonly used technique for elemental determination, graphite furnace-atomic absorption spectrometry (GFAAS) ${ }^{6}$ is preferred for aluminum, being a refractory element, due to the former's poor atomization efficiency and thus low sensitivity. Nonetheless, GFAAS is expensive, requires extensive experience to generate reproducible results, and is not available in small analytical laboratories. The techniques of choice for determining aluminum and its compounds in personal care products, including APPs, are high-performance liquid chromatography with ultraviolet/visible detection (HPLC-UV/Vis), ${ }^{7,8}$ flow injection-UV/Vis spectrophotometry, ${ }^{9}$ and flow-through potentiometry. ${ }^{10}$ Despite their numerous benefits, the high operating costs and high level of expertise required to use them make it difficult for small laboratories to purchase and use them efficiently. Furthermore, these instruments are electricity-dependent and not designed for on-field analysis, necessitating the development of alternative techniques. Miniaturized detection techniques that overcome these limitations have recently received special attention. A colorimetric solid-phase extraction method was proposed for the determination of aluminum, in which a membrane disk loaded with the colorimetric reagent pyridoxal salicyloylhydrazone allowed the extraction of the metal complex before its detection using a miniature fiber optic spectrometer." To detect the aluminum complex in the visible region, a paper platform with alizarin S as a chromogenic reagent in a spot test was used in conjunction with diffuse reflectance spectroscopy using a portable spectrophotometer. ${ }^{12}$

Digital image colorimetry (DIC) is a new colorimetric technique that utilizes the basic red-green-blue (RGB) channels of images of a colored analyte solution captured by a digital camera, webcam, hand scanner, or smartphone camera.13,14 Smartphones are the best image acquisition tools for this purpose because of their superior photography functions, software, and portability for image processing. Smartphone
DIC (SDIC) has been applied for the determination of total iron, ${ }^{15}$ iron (II), ${ }^{16}$ chromium (VI), ${ }^{17}$ arsenic (III), ${ }^{18}$ cobalt (II) ${ }^{19}$ and boron ${ }^{20}$ in addition to several organic analytes in various samples. To the best of our knowledge, this is the first study on the use of SDIC for the determination of aluminum.

In this study, an SDIC method is proposed for the determination of aluminum in APP samples after chelating it with quercetin to form a yellow complex that can be easily detected by a smartphone camera. The results of SDIC were compared with HPLC-diode-array detection (HPLC-DAD) method for accuracy check.

\section{MATERIALS AND METHODS}

\section{Chemicals and reagents}

All the reagents used were of analytical grade unless otherwise indicated. Acetic acid, HPLC-grade acetonitrile, aluminum nitrate nonahydrate, disodium phosphate, ethanol, hydrochloric acid, monosodium phosphate, nitric acid, quercetin, and sodium acetate were obtained from Sigma-Aldrich (Steinheim, Germany), while trifluoroacetic acid was obtained from Fluka (Buchs, Germany). Deionized (DI) water (18.2 M $\Omega-\mathrm{cm}$ ), purified with Pure Lab Ultra Analytic (ELGA LabWater, High Wycombe, UK), was used for the preparation of all aqueous solutions.

\section{Instrumentation}

A homemade colorimetric box with the dimensions of $20 \times 15$ $\times 8 \mathrm{~cm}^{3}$ was used. The white interior walls provided uniform illumination. Sample solutions were transferred into a quartz UV/Vis microcuvette (Hellma, Kruibeke, Belgium) and placed inside the box $10.0 \mathrm{~cm}$ from the detection camera and $11.0 \mathrm{~cm}$ from a 1.2V/1300 mA battery-powered white light-emitting diode that illuminated the sample solution. Images were captured with the flash being turned off. A diagram of the colorimetric box is shown in Figure 1. Digital images were captured using an SM-C9 smartphone, equipped with a 16 MP rear camera with a resolution of $4608 \times 3456$ pixels. Images were processed using

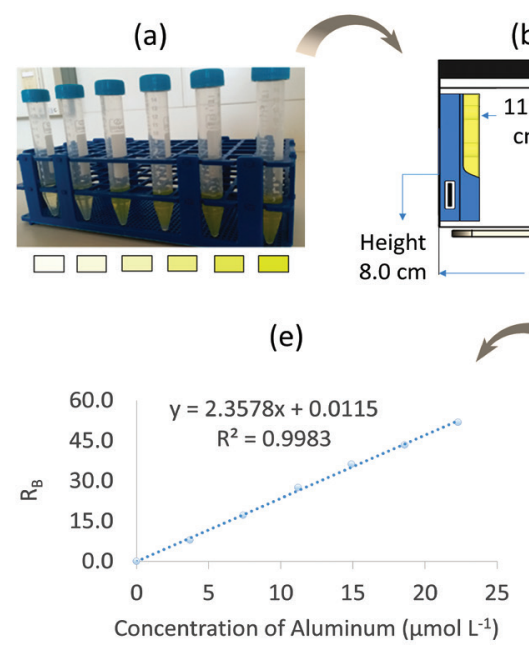

(b)

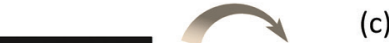

$.0 \rightarrow$

$\quad 15.0 \mathrm{~cm}$ $10.0 \mathrm{~cm}$

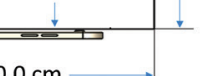

(c)

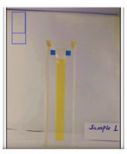

(d)

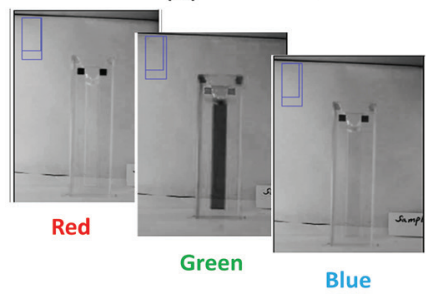

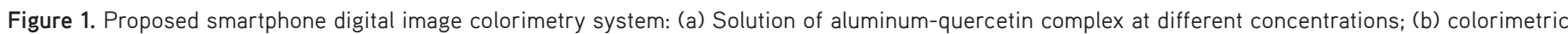

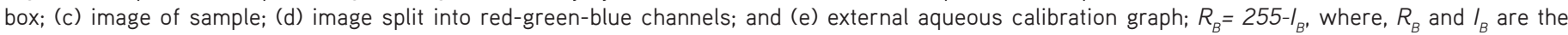
response and intensity of the analyte solution in the $\mathrm{B}$ channel, respectively 
the freely downloadable software ImageJ (PC version, 1.52a, Java 1.8.0_212, 64 bit) from the National Institutes of Health, USA. ${ }^{21}$ An HPLC instrument (1200 Series, Agilent Technologies, Santa Clara, CA, USA), equipped with a degasser, a quaternary pump, an autosampler, a column thermal jacket and a DAD was used for accuracy check of the method.

\section{Standard solutions of aluminum}

A $3.7 \mathrm{mmol} \mathrm{L}^{-1}$ stock solution of aluminum was prepared by dissolving an appropriate mass of aluminum nitrate nonahydrate in $0.10 \mathrm{~mol} \mathrm{~L}^{-1}$ hydrochloric acid solution, from which a 0.37 $\mathrm{mmol} \mathrm{L}^{-1}$ intermediate standard solution was prepared in the same diluent. Working standard solutions were prepared in the ranges of 1.7-25.0 $\mu \mathrm{mol} \mathrm{L}^{-1}$ for SDIC and 3.3-60 $\mu \mathrm{mol} \mathrm{L}^{-1}$ for HPLC-DAD in the same diluent. A $3.3 \mathrm{mmol}^{-1}$ stock solution of quercetin was prepared by dissolving an appropriate mass of the solid in ethanol/DI water $(60 / 40 \%, v / v)$. The $\mathrm{pH}$ was adjusted to 5.5 with a $1.0 \mathrm{~mol} \mathrm{~L}^{-1}$ acetate buffer solution.

\section{Sample preparation}

Five APP samples of various brands were obtained from local groceries and pharmacies in Nicosia, TRNC. The samples were digested using a previously developed method ${ }^{22}$ with some modifications. Briefly, $0.25 \pm 0.01 \mathrm{~g}$ of each sample was weighed and digested in $3.0 \mathrm{~mL}$ of aqua regia in PTFE cups for $2.0 \mathrm{~h}$ at $100^{\circ} \mathrm{C}$ in a closed-vessel digestion block. After allowing the samples to cool down to room temperature, they were filtered through a $0.22 \mu \mathrm{m}$ Whatman filter paper into a $25.0 \mathrm{~mL}$ volumetric flask and the volume was completed to the mark with DI water. From this solution, $1.0 \mathrm{~mL}$ was transferred into another $25.0 \mathrm{~mL}$ volumetric flask and the volume was made up to the mark with DI water. This solution will be referred to as the sample solution henceforth.

\section{Complexation reaction and smartphone digital image colorimetry}

For complexation, $250 \mu \mathrm{L}$ of the $3.3 \mathrm{mmol} \mathrm{L}^{-1}$ quercetin solution was added to $50.0 \mu \mathrm{L}$ of the sample solution in a $15 \mathrm{~mL}$ screw capped graduated polypropylene centrifuge tube. The mixture was made up to $3.0 \mathrm{~mL}$ with acetate buffer solution $(\mathrm{pH} 5.5)$. After the solution was vortexed for $1.0 \mathrm{~min}$, a portion (ca. 100 $\mu \mathrm{L}$ ) was transferred into a quartz UV/Vis cuvette for SDIC analysis.

\section{Chromatographic conditions}

The aluminum-quercetin complex and the excess ligand were separated using a reversed-phase column (Agilent Eclipse XDB-C18 $4.6 \mathrm{~mm}$ ID x $150 \mathrm{~mm}, 5 \mu \mathrm{m}$, Agilent Technologies, Santa Clara, CA, USA), a gradient elution consisting of $0.5 \%$ trifluoroacetic acid in DI water, $\mathrm{pH} 1.40$ (solvent $\mathrm{A}$ ) and acetonitrile (solvent B), with a gradient program of $10 \%$ solvent $\mathrm{B}$ at $0 \mathrm{~min}$ to $80 \%$ solvent $\mathrm{B}$ within $10 \mathrm{~min}$ at a flow rate of 1.0 $\mathrm{mL} \mathrm{min}{ }^{-1}$. Separation temperature and the injection volume were set at $30^{\circ} \mathrm{C}$ and $20 \mu \mathrm{L}$, respectively. The maximum absorption wavelengths of the complex and ligand were 415.0 and 374.0 $\mathrm{nm}$, respectively. The chromatograms obtained are given in Figure 2.

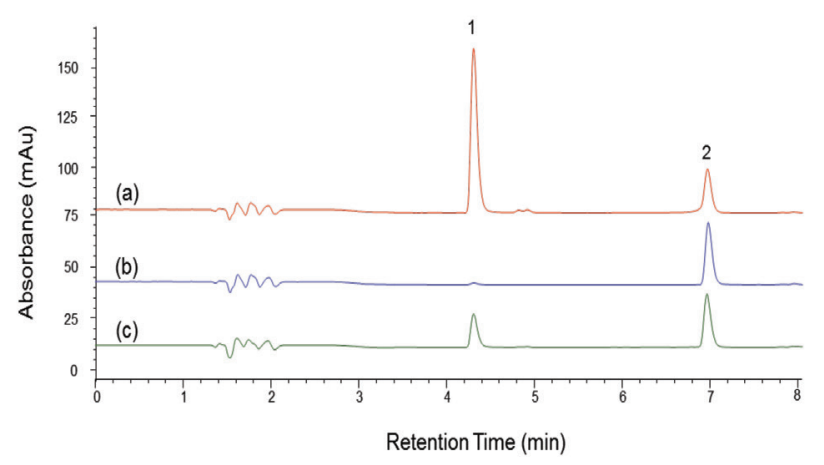

Figure 2. HPLC-DAD chromatograms: (a) Aluminum standard in 0.10 $\mathrm{M}$ hydrochloric acid $(50 \mu \mathrm{M})$; (b) quercetin $(100 \mu \mathrm{M})$; (c) antiperspirant product. Separation conditions: Column, Agilent Eclipse XDB-C18. $4.6 \mathrm{~mm}$ ID $\times 150 \mathrm{~mm}, 5 \mu \mathrm{m}$, gradient mobile phase with $0.5 \%$ trifluoroacetic acid in $\mathrm{DI}$ water, $\mathrm{pH} 1.4$ (solvent $\mathrm{A}$ ) and acetonitrile (solvent $\mathrm{B}$ ), $10 \% \mathrm{~B}$ at 0 min to $80 \% \mathrm{~B}$ within $10 \mathrm{~min}$ at a flow rate of $1.0 \mathrm{~mL} \mathrm{~min}{ }^{-1}$ column temperature, $30^{\circ} \mathrm{C}$, injection volume, $20 \mu \mathrm{L}$, detection wavelength, $415 \mathrm{~nm}$. Peaks: 1 , aluminum-quercetin complex, and 2 , quercetin

HPLC: High-performance liquid chromatography, DAD: Diode-array detection

\section{Statistical analysis}

Upon splitting the images into their RGB channels, the mean histogram values from the $B$ channel were used for calibration and quantitation throughout the analysis. For statistical analysis, a single-factor analysis of variance test (ANOVA) in Microsoft Office Excel (2013 Windows, Microsoft Corporation, WA, USA) was used; a $p$ value less than 0.05 was considered statistically significant.

\section{RESULTS AND DISCUSSION}

\section{Optimization of smartphone digital image colorimetry conditions}

\section{Data processing}

The mean value of each channel was obtained from its histogram and the B channel, giving the highest intensity, was used for the rest of the experiments. Because in the RGB model, the more intense the color, the lower the values within the range of $0-255$, the value obtained from the histogram required additional processing to obtain a positive slope. Beer's Law, represented by the equation $R=\log (I / l)$, where $R$ is the response, $I_{0}$ is the mean intensity of the blank, and $I$ is the mean intensity of the analyte, all measured from the same channel, has been used to process RGB data in the literature. ${ }^{23}$ The equations $R=255-I_{,}, 24$ and $R=I_{0}-I_{b}$ were also used, where, $I_{0}$ and $I_{b}$ are the mean intensity of the blank and the analyte solutions in the blue channel, respectively. ${ }^{25}$ In this study, the data were processed using equation 1 .

$R_{B}=225-I_{B}$

equation 1

where, $R_{B}$ and $I_{B}$ are the response and intensity of the analyte solution in the $B$ channel, respectively. 


\section{Detection camera and region of interest}

The overall quality of an image is influenced by several factors, such as resolution, aperture, specifications of the light sensor as well as the algorithm applied for image processing. ${ }^{26}$ The effect of camera type on the response was assessed using four different phones, namely, SM-C9, Techno p-3, SM-S7, and iPad 1460 with camera resolutions of 16 MP, 13 MP, 12 $\mathrm{MP}$, and $5 \mathrm{MP}$, respectively. The response increased as the resolution increased (Figure $3 a$ ), indicating that this parameter is important in determining the image quality. Therefore, SMC9 was used for further analysis. The digital images captured for sample solutions were processed within a defined region of interest ranging from 400 to $14400 \mathrm{px}^{2}$. The results revealed no significant differences in the response, owing primarily to the homogeneity of the sample solutions (Figure $3 \mathrm{~b}$ ). An area of $6400 \mathrm{px}^{2}$ was used throughout the analysis.

\section{Position of camera and cuvette}

Compared to the side position, the top position produced blurred images and a slightly lower response (Figure 3c). As a result, the side position was used for further analysis. The effect of the distance between the sample solution and the detection camera was investigated over a range of $8.0-12.0 \mathrm{~cm}$ with the image blurring below $8.0 \mathrm{~cm}$. The response remained nearly constant throughout the entire range under study (Figure $3 d$ ), indicating that the detection camera's maximum autofocus efficiency was achieved within this distance. For the following experiments, an optimal distance of $10.0 \mathrm{~cm}$ was chosen between the detection camera and the sample solution.

\section{Optimization of complexation conditions}

\section{Sample $p H$}

$\mathrm{pH}$ of the sample solution affects both the formation of a stable complex and the form of the analyte before complexation.
Aluminum exists primarily in its trivalent form under acidic conditions, whereas increasing the $\mathrm{pH}$ leads to the formation of insoluble aluminum hydroxide at neutral $\mathrm{pH} .{ }^{8}$ The effect of $\mathrm{pH}$ on the analytical response was studied over a $\mathrm{pH}$ range of 4.5 to 6.5 . The solution was colorless at $\mathrm{pH}$ less than 4.0 and an unstable yellow color formed at $\mathrm{pH}$ greater than 7.5. The response improved up to $\mathrm{pH} 5.5$, beyond which, it declined and remained almost constant (Figure 4a). A similar result was obtained in a previous study for the complexation $\mathrm{pH}$ of aluminum with quercetin. ${ }^{8}$ As a result, $\mathrm{pH} 5.5$ was deemed optimal throughout the study.

\section{Concentration of the ligand}

To ensure that the maximum yield of the complexation reaction was achieved, the addition of an excessive amount of quercetin is necessary. The effect of the ligand concentration was carried out by using a fixed concentration of aluminum $\left(0.31 \mathrm{mmol} \mathrm{L^{-1 }}\right)$, in a $3.0 \mathrm{~mL}$ sample solution buffered at $\mathrm{pH} 5.5$, and varying the concentration of quercetin from 0.06 to $0.50 \mathrm{mmol} \mathrm{L}^{-1}$. The response increased with increasing the concentration of quercetin up to $0.28 \mathrm{mmol} \mathrm{L}^{-1}$, after which it remained constant, indicating that the optimum molar ratio of metal to ligand was reached, which was in accordance with the theoretical stoichiometric molar ratio of 1:1 between aluminum and quercetin, as also found experimentally in a previous study. ${ }^{7}$ Therefore, the optimum concentration of quercetin was taken as $0.28 \mathrm{mmol} \mathrm{L}^{-1}$ (Figure $4 \mathrm{~b}$ ).

\section{Sample volume and complexation time}

Sample volume affects the concentration of the aluminumquercetin complex in the final solution. The effect of increasing the sample volume was investigated from 3.0 to $7.0 \mathrm{~mL}$. Notably, $3.0 \mathrm{~mL}$ was the minimum sample volume suitable to obtain a buffered solution after acid digestion of the real (a)

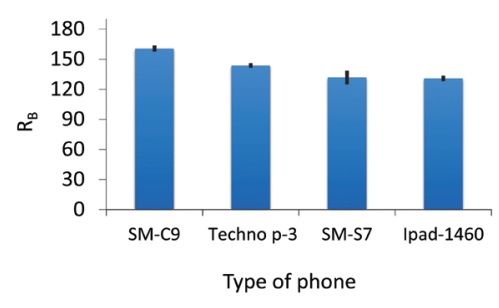

(c)

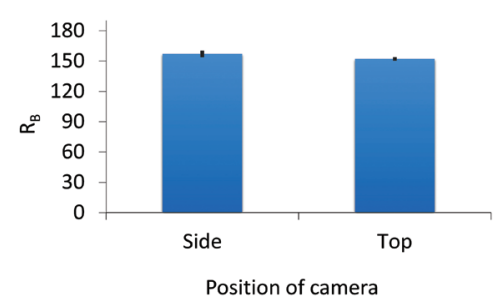

(b)

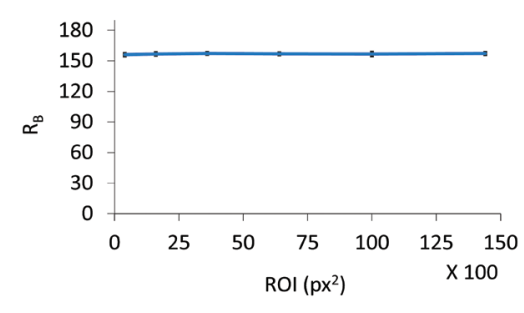

(d)

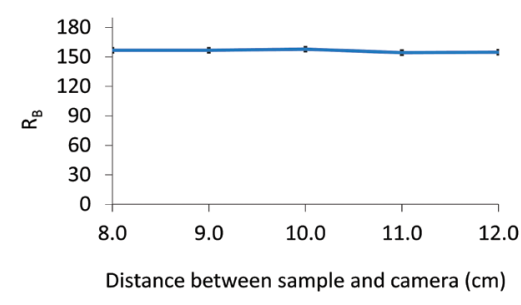

Figure 3. Optimization of smartphone digital image colorimetry parameters: (a) Type of phone; (b) area of region of interest; (c) position of camera; (d) and distance between sample and camera. Optimum complexation conditions: Sample pH 5.5; concentration of ligand, $0.28 \mathrm{mmol}^{-1}$; volume of sample solution, $3.0 \mathrm{~mL}$; and complexation time, $1.0 \mathrm{~min} ; R_{B}=255-I_{B}$, where, $R_{B}$ and $I_{B}$ are the response and intensity of the analyte solution in the $B$ channel, respectively 
samples. Expectedly, the response decreased with an increase in the volume of the sample solution due to dilution of the metal complex in the final solution (Figure 4c). As a result, the optimum sample volume was selected as $3.0 \mathrm{~mL}$. The time interval between adding the ligand to the sample solution and detecting the yellow complex was defined as the complexation time, which corresponded to the vortex mixing period. The effect of complexation time was studied over the range of 1.0$5.0 \mathrm{~min}$. The addition of the ligand resulted in instantaneous formation of a stable complex, as indicated by its consistent yellow (Figure $4 \mathrm{~d}$ ). Therefore, an optimum complexation time was selected as 1.0 min to ensure good repeatability.

\section{Analytical performance}

An aqueous calibration curve was plotted using standard aluminum solutions at concentrations ranging from 1.7 to
$25.0 \mu \mathrm{mol} \mathrm{L}^{-1}$ to assess the analytical performance of the proposed method. A linear calibration graph was obtained with a coefficient of determination $\left(R^{2}\right)$ of 0.9981 (Table 1). Repeatability was evaluated in terms of intraday and interday precision. The results, expressed as a percentage relative standard deviation were less than $2.2 \%$ and $3.1 \%$, respectively. The limit of detection (LOD), calculated based on $3 \mathrm{~S}_{b} / \mathrm{m}$, where $\mathrm{S}_{\mathrm{b}}$ is the standard deviation of the intercept and $\mathrm{m}$ is the slope of the regression equation, was found as $0.5 \mu \mathrm{mol} \mathrm{L}^{-1}\left(0.2 \mu \mathrm{g} \mathrm{g}^{-1}\right)$ and the limit of quantitation (LOQ), based on $10 \mathrm{~S}_{\mathrm{b}} / \mathrm{m}$, was found to be $1.7 \mu \mathrm{mol} \mathrm{L} \mathrm{L}^{-1}\left(0.7 \mu \mathrm{g} \mathrm{g}^{-1}\right)$.

\section{Determination of aluminum in antiperspirant products}

All five of the analyzed samples were found to contain aluminum at concentrations in the range of 2.4 to $3.5 \%(\mathrm{w} / \mathrm{w})$ (Table 2$)$. (a)

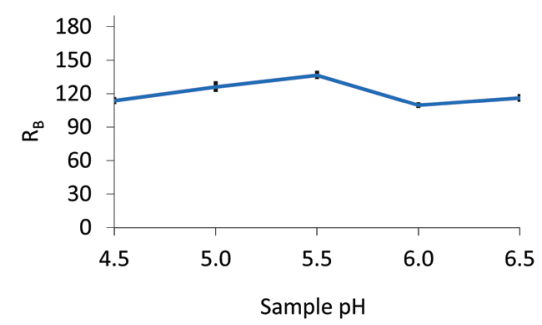

(c)

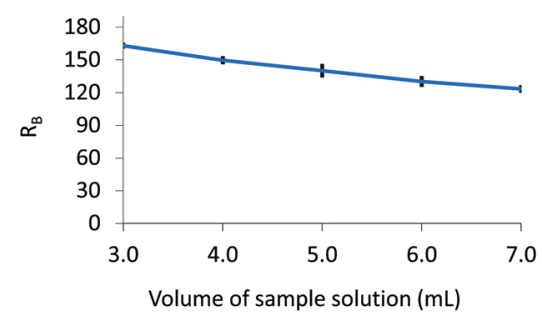

(b)

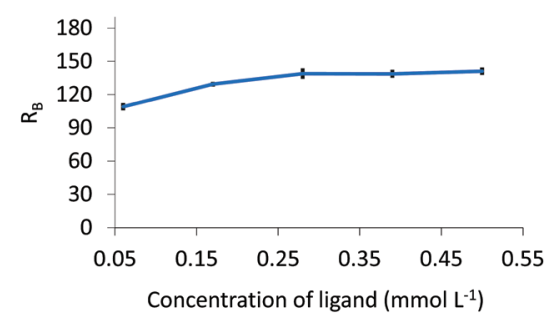

(d)

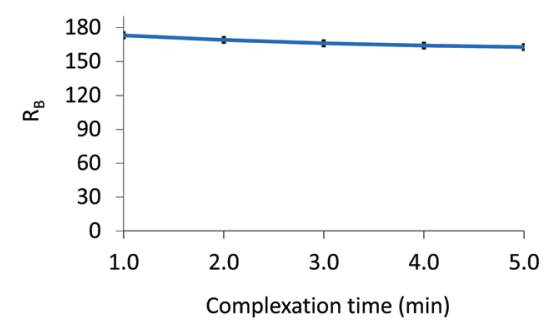

Figure 4. Optimization of complexation parameters: (a) Sample $\mathrm{pH}$; (b) concentration of ligand; (c) volume of sample solution; (d) complexation time. Optimum smartphone digital image colorimetry conditions: Type of phone, SM-C9; area of region of interest, 6400 px $^{2}$; position of camera, side; distance between sample and camera, $10.0 \mathrm{~cm} ; R_{B}=255-I_{B}$, where, $R_{B}$ and $I_{B}$ are the response and intensity of the analyte solution in the $B$ channel, respectively

Table 1. Comparison of the analytical figures of merit of the proposed smartphone-digital image colorimetry method with high-performance liquid chromatography-diode-array detection for the determination of aluminum in antiperspirant products

\begin{tabular}{|c|c|c|c|c|c|c|c|}
\hline \multirow{2}{*}{$\begin{array}{l}\text { Analytical } \\
\text { technique }\end{array}$} & \multirow{2}{*}{ Regression equation ${ }^{a}$} & \multirow{2}{*}{$\mathrm{R}^{2 \mathrm{~b}}$} & \multirow{2}{*}{$\operatorname{LOD}^{c}$} & \multirow{2}{*}{$\mathrm{LOQ}^{\mathrm{d}}$} & \multirow{2}{*}{ LDR $^{e}$} & \multicolumn{2}{|l|}{$\% R_{S}{ }^{f}$} \\
\hline & & & & & & Intraday & Intraday \\
\hline HPLC-DAD & $Y=1.38( \pm 0.02) x+0.93( \pm 0.45)$ & 0.9993 & $1.0\left(0.3 \mu g^{-1}\right)$ & $3.3\left(1.1 \mu \mathrm{g} \mathrm{g}^{-1}\right)$ & $3.3-60.0$ & 2.3 & 3.0 \\
\hline SDIC & $Y=2.36( \pm 0.03) x-0.0016( \pm 0.40)$ & 0.9981 & $0.5\left(0.2 \mu g^{-1}\right)$ & $1.7\left(0.7 \mu g^{-1}\right)$ & $1.7-25.0$ & 2.2 & 3.1 \\
\hline
\end{tabular}

${ }^{a}$ Response $=$ slope $( \pm$ SD $) \times$ [aluminum concentration $\left(\mu \mathrm{mol} \mathrm{L}^{-1}\right)+$ intercept $( \pm \mathrm{SD})$

${ }^{b}$ Coefficient of determination

'Limit of detection ( $\left.\mu \mathrm{mol} \mathrm{L} \mathrm{L}^{-1}\right)$

dLimit of quantitation $\left(\mu \mathrm{mol} \mathrm{L}^{-1}\right)$

e Linear dynamic range $\left(\mu \mathrm{mol} \mathrm{L}^{-1}\right)$

fPercentage relative standard deviation, $\mathrm{n}: 3$

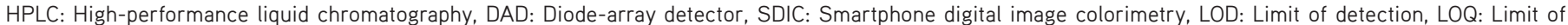
quantitation, RSD: Relative standard deviation, SD: Standard deviation 
Table 2. Percentage recoveries of aluminum from antiperspirant products using smartphone digital image colorimetry and high-performance liquid chromatography-diode-array detection obtained with standard-addition and recovery tests

\begin{tabular}{|c|c|c|c|c|}
\hline Sample ${ }^{a}$ & $\begin{array}{l}\text { Added } \\
(\%, w / w)\end{array}$ & $\begin{array}{l}\text { Found (SDIC) } \\
(\%, w / w)\end{array}$ & $\% R^{b}$ & $\begin{array}{l}\text { Found (HPLC-DAD) } \\
(\%, w / w)\end{array}$ \\
\hline \multirow{4}{*}{ APP1 } & - & $2.9( \pm 0.2)$ & - & \multirow{4}{*}{$3.2( \pm 0.2)$} \\
\hline & 1.0 & 4.0 & 105.0 & \\
\hline & 3.0 & 5.8 & 95.0 & \\
\hline & 5.0 & 7.5 & 90.2 & \\
\hline \multirow{4}{*}{ APP2 } & - & $2.4( \pm 0.9)$ & - & \multirow{4}{*}{$3.3( \pm 0.2)$} \\
\hline & 1.0 & 3.2 & 80.0 & \\
\hline & 3.0 & 5.6 & 109.7 & \\
\hline & 5.0 & 7.2 & 97.2 & \\
\hline \multirow{4}{*}{ APP3 } & - & $2.7( \pm 0.4)$ & - & \multirow{4}{*}{$3.2( \pm 0.2)$} \\
\hline & 1.0 & 3.6 & 85.0 & \\
\hline & 3.0 & 5.7 & 99.0 & \\
\hline & 5.0 & 8.1 & 107.2 & \\
\hline \multirow{4}{*}{ APP4 } & - & $2.6( \pm 0.3)$ & - & \multirow{4}{*}{$2.4( \pm 0.1)$} \\
\hline & 1.0 & 3.5 & 89.0 & \\
\hline & 3.0 & 5.8 & 105.0 & \\
\hline & 5.0 & 8.0 & 107.8 & \\
\hline \multirow{4}{*}{ APP5 } & - & $3.3( \pm 0.2)$ & - & \multirow{4}{*}{$3.5( \pm 0.1)$} \\
\hline & 1.0 & 4.3 & 100.0 & \\
\hline & 3.0 & 6.2 & 96.0 & \\
\hline & 5.0 & 7.8 & 90.2 & \\
\hline
\end{tabular}

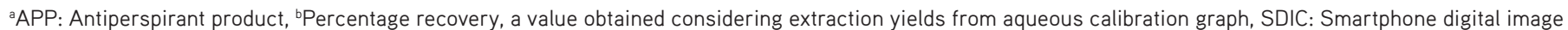
colorimetry, HPLC: High-performance liquid chromatography, DAD: Diode-array detector

The accuracy of SDIC was checked using an addition-recovery test by spiking the samples with aluminum (as aluminum nitrate nonahydrate to the genuine samples) at three concentration levels (i.e., 1.0, 3.0, and $5.0 \% \mathrm{w} / \mathrm{w}$ ). The percentage absolute recoveries (\%R), calculated from the aqueous calibration curve, were found to range between 80.0 and 109.7 (Table 2). An independent HPLC-DAD study found no statistically significant difference between the results obtained with both techniques ( $p>0.05$ ) for all samples (Table 2), indicating good accuracy of the proposed SDIC method.

\section{Comparison with other methods}

The proposed SDIC method was compared with the HPLC-DAD method in terms of linearity, sensitivity, linear dynamic range, precision, analysis time and organic solvent consumption (Tables 1, 3). The main advantages of SDIC over HPLC-DAD are the significantly lower cost of purchase, operation and maintenance as well as the shorter analysis time, i.e., 1 vs. 8 min, respectively (Table 3 ). Similarly, the proposed method was compared to other methods used for the determination of aluminum in personal care products. The results, summarized in Table 3, reveal that the proposed method is superior to the others in terms of cost, degree of greenness, and ease of implementation. Furthermore, it outperformed the others due to its zero organic solvent consumption, one-minute analysis time, and low energy dependence. Although paper platform for colorimetric determination-diffusive reflectance spectroscopy did not require any organic solvents, the analysis time was rather long. ${ }^{12}$ The analysis time with flow-through potentiometric sensors was only $0.5 \mathrm{~min}$, but it required $3 \mathrm{~mL}$ of organic solvents per sample. ${ }^{10}$ SDIC was more sensitive than the other methods except for dispersive liquid-liquid microextraction$\mathrm{UV} / \mathrm{Vis}^{27}$ but the analysis time was longer.

\section{CONCLUSION}

In this study, SDIC was developed for the determination of aluminum in APPs. Quercetin was used as a ligand to form an easily detectable yellow complex with aluminum. The proposed method could be used to accurately determine aluminum in genuine samples, as demonstrated by HPLC-DAD and additionrecovery tests. In comparison to the latter method and others used in the literature for determining aluminum in personal care products including antiperspirants, the proposed method 
Table 3. Comparison of smartphone digital image colorimetry with other methods for the determination of aluminum in different types of samples

\begin{tabular}{|c|c|c|c|c|c|c|c|}
\hline Method $^{\mathrm{a}}$ & Sample & $\begin{array}{l}\text { Analysis time } \\
\text { (min) }\end{array}$ & $\begin{array}{l}V_{\text {org. }}{ }^{b} \\
(m L)\end{array}$ & $\begin{array}{l}\mathrm{LOD}^{\mathrm{c}} \\
\left(\mu \mathrm{g} \mathrm{mL}^{-1}\right)\end{array}$ & $\mathrm{R}^{2 \mathrm{~d}}$ & RSDe\% & References \\
\hline CSPE-DRS & $\begin{array}{l}\text { Cookware, antacids, } \\
\text { hygienic care products }\end{array}$ & 67 & 159 & 0.18 & 0.992 & 8.8 & 11 \\
\hline LLME-HPLC-UV/Vis & Antiperspirants & 46 & 12.5 & 1.24 & 0.997 & 5.5 & 8 \\
\hline $\mathrm{Fl-UV/Vis}$ & Antiperspirants & 44 & 60 & 0.0161 & 0.9992 & $<2$ & 9 \\
\hline PPC-DRS & Antiperspirants & 12 & 0 & 3.06 & 0.999 & $<5.0$ & 12 \\
\hline FTPS & Deodorants & 0.5 & 3 & 0.5 & 0.994 & 3 & 10 \\
\hline HPLC-DAD & Antiperspirants & 8 & 0 & 0.027 & 0.9993 & 3.0 & This study \\
\hline
\end{tabular}

${ }^{a}$ CSPE-DRS: Coupled colorimetric solid-phase extraction-diffusive reflectance spectroscopy, LLME-HPLC: Liquid-liquid extraction-high-performance liquid chromatography, FI-UV/Vis: Flow injection-ultraviolet/visible spectrophotometry, DLLME: Dispersive liquid-liquid microextraction, PPC: Paper platform for colorimetric determination, FTPS: Flow-through potentiometric sensors, DAD: Diode-array detector, SDIC: Smartphone digital image colorimetry, ${ }^{b}$ Volume of organic solvents consumed, 'Limit of detection, ${ }^{\mathrm{d} C}$ Coefficient of determination, ${ }^{\mathrm{P}}$ Percentage relative standard deviation, RSD: Relative standard deviation, LOD: Limit of detection

offers several significant advantages, including low operation and maintenance costs, short analysis time, high degree of greenness, simplicity of execution, zero organic solvent consumption, minimal energy dependency, portability, and high potential for on-field analysis. The obtained results show that SDIC is a viable alternative to sophisticated instrumental techniques that are not easily owned and/or operated by every laboratory for the determination of inorganic and organic analytes in various samples.

\section{ACKNOWLEDGMENTS}

The authors want to thank Prof. Dr. Nusret Ertaş from the Department of Analytical Chemistry, Faculty of Pharmacy, Gazi University, Ankara, Türkiye, for his insightful comments and suggestions throughout this work.

\section{Ethics}

Ethics Committee Approval: Not required.

Informed Consent: Not required.

Peer-review: Externally peer-reviewed.

\section{Authorship Contributions}

Concept: S.A., U.A., Design: S.A., U.A., Data Collection or Processing: S.A., U.A., J.C., Analysis or Interpretation: S.A., U.A., J.C., Literature Search: S.A., U.A., Writing: S.A., U.A., J.C.

Conflict of Interest: No conflict of interest was declared by the authors.

Financial Disclosure: The authors declared that this study received no financial support.

\section{REFERENCES}

1. Rekhi H, Kaur R, Rani S, Malik AK, Kabir A, Furton KG. Direct rapid determination of trace aluminum in various water samples with quercetin by reverse phase high-performance liquid chromatography based on fabric phase sorptive extraction technique. J Chromatogr Sci. 2018;56:452-460.

2. Laden K. Antiperspirants and deodorants ( $2^{\text {nd }}$ ed), CRC Press, Boca Raton, Florida; USA; 1999;15.

3. McGrath KG. Apocrine sweat gland obstruction by antiperspirants allowing transdermal absorption of cutaneous generated hormones and pheromones as a link to the observed incidence rates of breast and prostate cancer in the $20^{\text {th }}$ century. Med Hypotheses. 2009;72:665-674.

4. Krewski D, Yokel RA, Nieboer E, Borchelt D, Cohen J, Harry J, Kacew S, Lindsay J, Mahfouz AM, Rondeau V. Human health risk assessment for aluminium, aluminium oxide, and aluminium hydroxide. J Toxicol Environ Health B Crit Rev. 2007;10(Suppl 1):1-269. Erratum in: J Toxicol Environ Health B Crit Rev. 2008;11:147.

5. Ahmed SS, Santosh W. Metallomic profiling and linkage map analysis of early Parkinson's disease: a new insight to aluminum marker for the possible diagnosis. PLoS One. 2010;5:e11252.

6. Castilho INB, de Quadros DPC, Mior R, Welz B, Carasek E, Borges DLG. Determination of aluminum in moisturizing body lotions using graphite furnace atomic absorption spectrometry. Anal Methods. 2015;7:96369640.

7. Lian H, Kang Y, Bi S, Arkin Y, Shao D, Li D, Chen Y, Dai L, Gan N, Tian $L$. Direct determination of trace aluminum with quercetin by reversedphase high performance liquid chromatography. Talanta. 2004;62:43-50.

8. Kalogria E, Varvaresou A, Papageorgiou S, Protopapa E, Tsaknis I, Matikas A, Panderi I. Pre-column derivatization HPLC procedure for the 
quantitation of aluminium chlorohydrate in antiperspirant creams using quercetin as chromogenic reagent. Chromatographia. 2014;77:1275-1281.

9. López-Gonzálvez A, Ruiz MA, Barbas C. Validated flow-injection method for rapid aluminium determination in anti-perspirants. J Pharm Biomed Anal. 2008;48:340-346.

10. Hassan SSM, Kamel AH, Abd El-Naby H. Flow-through potentiometric sensors for alizarin red $\mathrm{s}$ dye and their application for aluminum determination. J Chin Chem Soc. 2014;61:295-302.

11. Castañeda-Loaiza V, Díaz-de-Alba MI, Granado-Castro MD, GalindoRiaño MD, Casanueva-Marenco MJ. Disposable optical sensor for Al(III) ions determination by coupled colorimetric solid-phase extractionreflectance spectroscopy in leachates from cookware, antacids and hygienic care products. Talanta. 2019;205: 120102.

12. Silvestre ALP, Milani MI, Rossini EL, Pezza L, Pezza HR. A paper platform for colorimetric determination of aluminum hydrochloride in antiperspirant samples. Spectrochim Acta A Mol Biomol Spectrosc. 2018;204:432-435

13. Tôrres AR, da Silva Lyra WD, de Andrade SIE, Andrade RAN, da Silva EC, Araújo MCU, da Nóbrega Gaiãob E. A digital image-based method for determining of total acidity in red wines using acid-base titration without indicator. Talanta. 2011;84:601-606.

14. Lin B, Yu Y, Cao Y, Guo M, Zhu D, Dai J, Zheng M. Point-of-care testing for streptomycin based on aptamer recognizing and digital image colorimetry by smartphone. Biosens Bioelectron. 2018;100:482-489.

15. Masawat $P$, Harfield A, Srihirun N, Namwong A. Green determination of total iron in water by digital image colorimetry. Anal Lett. 2017;50:173185.

16. Choodum A, Sriprom W, Wongniramaikul W. Portable and selective colorimetric film and digital image colorimetry for detection of iron. Spectrochim Acta A Mol Biomol Spectrosc. 2019;208:40-47.

17. Zarghampour F, Yamini Y, Baharfar M, Javadian G, Faraji M. On-chip electromembrane extraction followed by sensitive digital image-based colorimetry for determination of trace amounts of $\mathrm{Cr}(\mathrm{VI})$. Anal Method. 2020;12:483-490.

18. Choodum A, Jirapattanasophon V, Boonkanon C, Taweekarn T, Wongniramaikul W. Difluoroboron-curcumin doped starch film and digital image colorimetry for semi-quantitative analysis of arsenic. Anal Sci. 2020;36:577-582.

19. Lemos VA, Junior IVS, Santos LB, Barreto JA, Ferreira SLC. A new simple and fast method for determination of cobalt in vitamin B12 and water samples using dispersive liquid-liquid microextraction and digital image analysis. Water Air Soil Pollut. 2020:231.

20. Boonkanon C, Phatthanawiwat K, Wongniramaikul W, Choodum A. Curcumin nanoparticle doped starch thin film as a green colorimetric sensor for detection of boron. Spectrochim Acta A Mol Biomol Spectrosc. 2020;224:117351.

21. Rueden CT, Schindelin J, Hiner MC, DeZonia BE, Walter AE, Arena ET, Eliceiri KW. ImageJ2: ImageJ for the next generation of scientific image data. BMC Bioinformatics. 2017;18:529.

22. Lorenz C, Hagendorfer H, von Goetz N, Kaegi R, Gehrig R, Ulrich A, Scheringer $M$, Hungerbühler K. Nanosized aerosols from consumer sprays: experimental analysis and exposure modeling for four commercial products. J Nanopart Res. 2011;13:3377-3391.

23. Kohl SK, Landmark JD, Stickle DF. Demonstration of absorbance using digital color image analysis and colored solutions. J Chem Educ. 2006;83:644-646.

24. Porto ISA, Neto JHS, dos Santos LO, Gomes AA, Ferreira SLC Determination of ascorbic acid in natural fruit juices using digital image colorimetry. Microchem J. 2019;149:04031.

25. Caleb J, Alshana U, Ertaș N. Smartphone digital image colorimetry combined with solidification of floating organic drop-dispersive liquidliquid microextraction for the determination of iodate in table salt. Food Chem. 2021;336:127708.

26. Quesada-González D, Merkoçi A. Mobile phone-based biosensing: an emerging "diagnostic and communication" technology. Biosens Bioelectron. 2017;92:549-562.

27. Birgani NT, Elhami S. Development of a dispersive liquid-liquid microextraction method combined with UV-visible spectrophotometry for determination of trace aluminum(III) in water, wastewater, food, biological, and pharmaceutical samples. J AOAC Int. 2017;100:224-229. 